\title{
Hybrid Systems: Exploring Decentralized Water Management at an Urban Residence
}

\author{
DEVKI DESAI ${ }^{1}$, JORDAN OCCENA ${ }^{1 *}$, HANNAH ROCKWELL ${ }^{1}$,
} U-M LIVING BUILDINGS TEAM ${ }^{1}$

Volume 3, Spring 2015

http://dx.doi.org/10.3998/mjs.12333712.0003.006

'University of Michigan College of Engineering BLUElab, 2190 G.G. Brown Laboratory, 2350 Hayward, Ann Arbor MI 48109

${ }^{\star}$ Corresponding author: Jordan Occena, joccena@umich.edu

\section{ABSTRACT}

Once considered impossible, "net-zero energy" design has become an increasingly accessible option in green building practice. The popular phrase describes buildings which use passive design principles, limit plug loads, and use on-site energygeneration devices such as solar panels to produce at least as much energy as the building consumes per year. Energy production and consumption are inextricably linked to the production and consumption of another valuable resource: water. The two resources should be considered in tandem to gain a clearer picture of the global optimum in a sustainable building design. However, "net-zero water" design has proven more elusive in practice.

Although water is often as readily available on-site as energy, it cannot be shared with the city grid, may not be of uniform quality across building sites, and cannot be stored without changes in quality. Despite these challenges, as our aging water infrastructure becomes increasingly stressed due to climate change-induced severe weather events, the concept of "net-zero water" design in buildings warrants consideration. Further, with existing buildings comprising the majority of our infrastructure, to wield a significant impact, "net-zero" must be considered in the context of retrofit.

The climate adaptation challenge of retrofitting the country's first net-zero en- 
ergy historic home to net-zero water standards has been underway in Ann Arbor since January 2013 in a collaborative effort by the U-M Living Buildings Team from the College of Engineering's BLUElab and the home's owners. The research team is analyzing water-consumption patterns, precipitation data, and runoff quality to design a rainwater harvesting system for the 114-year-old home. The system includes a custom rainwater catchment and purification system, an underground cistern, and stormwater detention basins planted with native prairie species. This project suggests methods of integrating decentralized water infrastructure into centralized systems within city limits, raises important issues to consider when designing combined net-zero energy and water systems, and reveals the need for regulatory improvements to accommodate these systems.

\section{Hybrid systems}

Once considered impossible, a "net-zero energy building" has become an increasingly off-the-shelf option in green design. Net-zero energy buildings use passive thermal design strategies and technology such as solar panels to produce the energy the building consumes annually within its site footprint. This has been achieved successfully at commercial and educational institutions (Nelson 2013, ILFI 2014) as well as single-family homes (Grable 2014). However, its resource-conserving analogue, "net-zero water" design, in which a building both harvests water and treats wastewater on-site, has proven more elusive. Overall, on-site energy generation necessitates off-site water use and on-site water use implies off-site energy expenditures, thus minimizing the overall environmental footprint warrants consideration of both resources.

Although water is often readily available on-site like energy, it cannot be shared with the city grid, may not be of uniform quality across building sites, and cannot be stored without changes in quality (Cascadia GBC 2011). In addition, our centralized water infrastructure is under stress due to the increasing frequency of climate change-induced extreme weather events (Aupperlee 2013) and the approaching end of the infrastructure service life in numerous U.S. cities (NYDEC 2014, ASCE 2014). Given the demand on older centralized systems, aquifers are overdrawn even in Michigan (Famiglietti 2014) and rainwater upon urban sites contributes disproportionately to low-quality surface runoff (Brabec et al. 2002). Net-zero water design in buildings presents an opportunity to mitigate both issues. Integrating efficient on-site resource harvesting systems into retrofits and forming 
a hybrid of centralized and decentralized energy and water infrastructure is key to future resilience in cities. Further, as existing buildings comprise the majority of our infrastructure, to wield a significant impact, change must be considered in the context of retrofit.

In response to these challenges, the U-M Living Buildings Team from the College of Engineering's BLUElab partnered with Matt and Kelly Grocoff in Ann Arbor, MI to explore the integration of a rainwater harvesting system with existing infrastructure at their historic, single-family, net-zero energy residence. The requirements of the Living Building Challenge certification program have served as design guidelines for the endeavor. Design constraints specific to this site include adherence to local historic district aesthetic guidelines, a lean annual net-zero energy budget, and city water regulations.

The 114-year-old home (Figures 1 and 2) originally operated an on-site well, a coal heating system and an outhouse. Over the years, solar panels, a groundcoupled heat pump and efficient appliances with municipal grid backup replaced on-site combustion. Eventually, the well was closed due to industrial groundwater contamination from decades of local Pall-Gelman plant operations, and the home was connected to municipal water. This project seeks a balance between decentralized and centralized resource management strategies at the site appropriate for the next century.

\section{System sizing}

The first step in designing a rainwater harvesting system is to determine the size of key system components, such as cistern volume and catchment area, based upon water use and supply patterns. Water use patterns were determined using the home water bill history, illuminating that consumption in the three person household, excluding landscape irrigation, was approximately 75 gallons per day (gpd). This figure is roughly one-third of the EPA-estimated average for households of this size (USEPA 2008), due to the home's low flow-rate fixtures and appliances. Further conservation including lowering all faucets to 0.5 gallons per minute (gpm), limiting shower duration, installing composting toilets, and some greywater reclamation, could allow water usage to drop as low as $35 \mathrm{gpd}$.

In sizing system components, this water consumption is balanced against the available water resources. Using 30 years of National Oceanic and Atmospheric Administration precipitation data for Ann Arbor (NOAA 2013) as input to the 


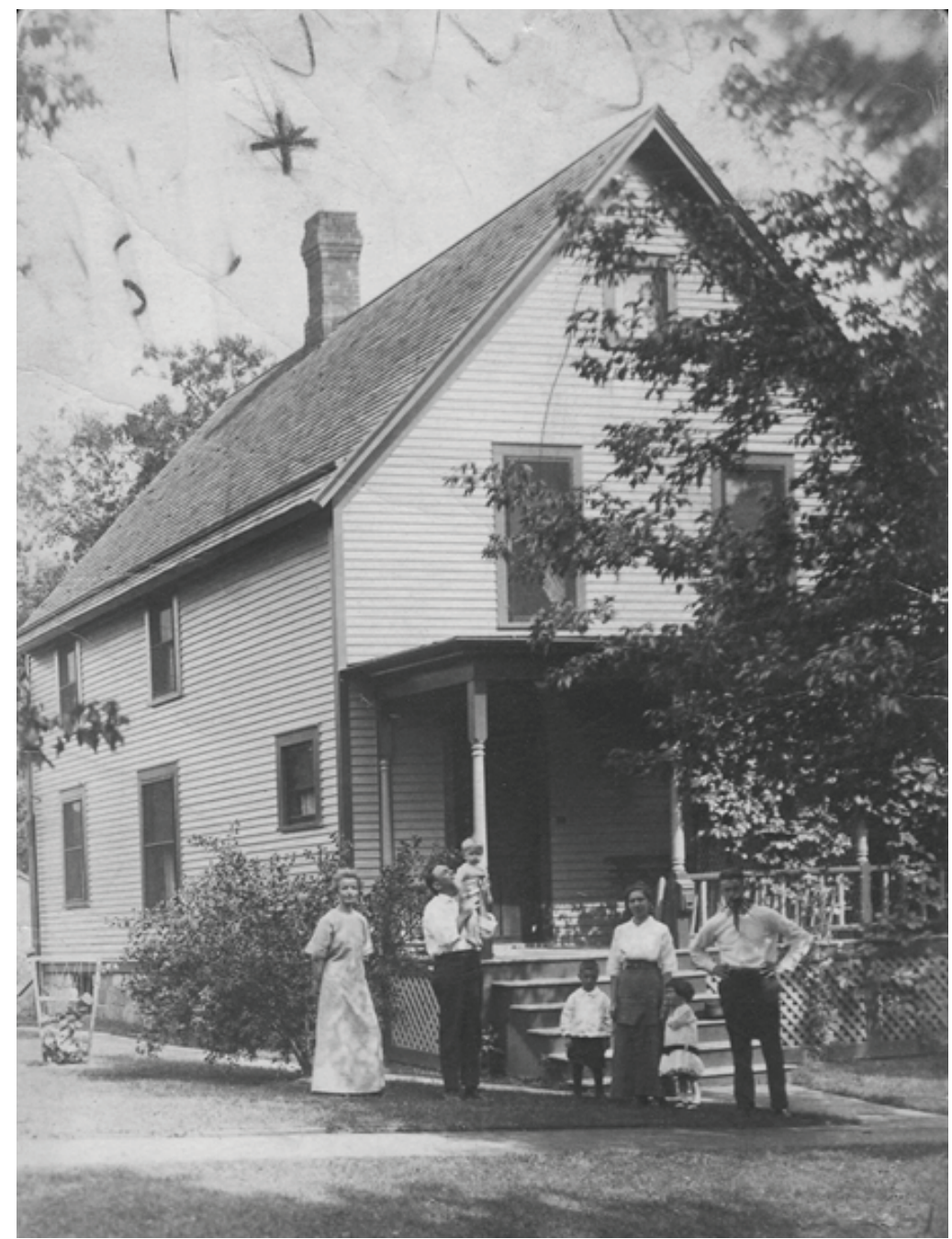

Figure 1. The site over a century ago.

US Department of Agriculture's runoff estimation procedure (USDA 1986), with a current roof area of $925 \mathrm{ft}^{2}$ and a $1 / 4$-acre site, we can estimate an average daily runoff of 27 gallons from the roof, 20 gallons from pavement and up to 15 gallons from non-native turfgrass.

The research team determined the appropriate combination of catchment area and underground cistern size by conducting simulations of a worst-case storm, dry spell, and typical daily cistern level simulation. According to simulations, a 2100 gallon cistern would be required to capture all the water that would land on the site within 24 hours during a 25 -year storm (i.e. a storm with a 4 percent chance of oc- 


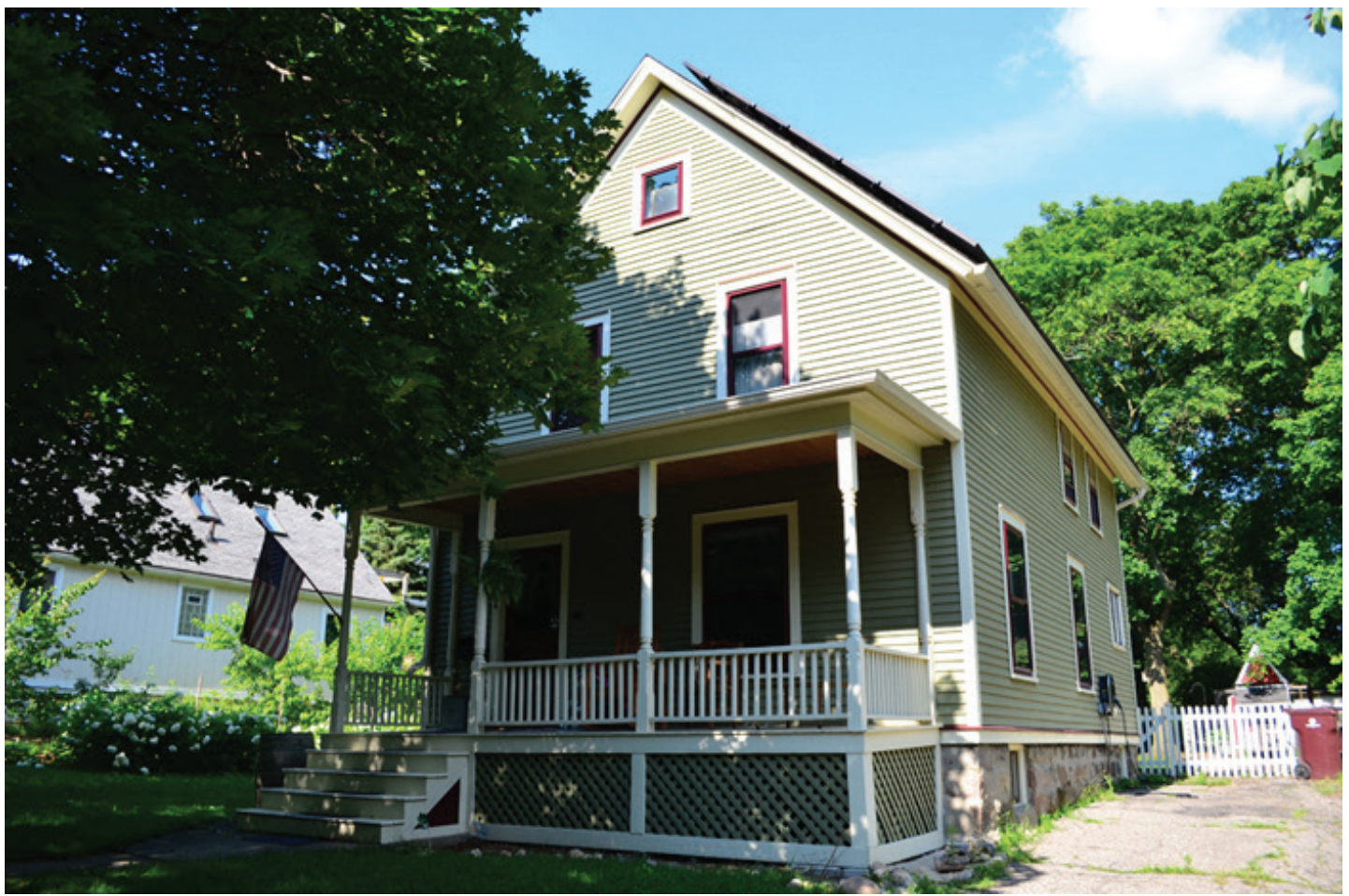

Figure 2. The site today.

curring in a given year). On the other hand, it might not rain for 2-3 consecutive weeks in a typical year and for even 7 weeks during a drought. If budgeting for 35 gpd usage, a cistern size of 1700 gallons at this site would provide the minimum storage volume required to manage a drought if the cistern was initially full. Extreme weather aside, simulating the daily dynamic cistern water level with 30-years of precipitation data suggested that it is possible to achieve uninterrupted net-zero water operation at the site during years of timely rainfall. Achieving this balance would require increasing the catchment area by $25 \%$ and installing a 2500 gallon underground polyethylene cistern, as indicated in Figure 3, and would meet the requirements of the storm and drought conditions as well.

\section{Retrofit challenges}

Once system sizing is complete, project designers can choose the roofing material. For a new-construction project, paint-free acrylic-coated metal shingles are 
Cistern Size and SpeCifications

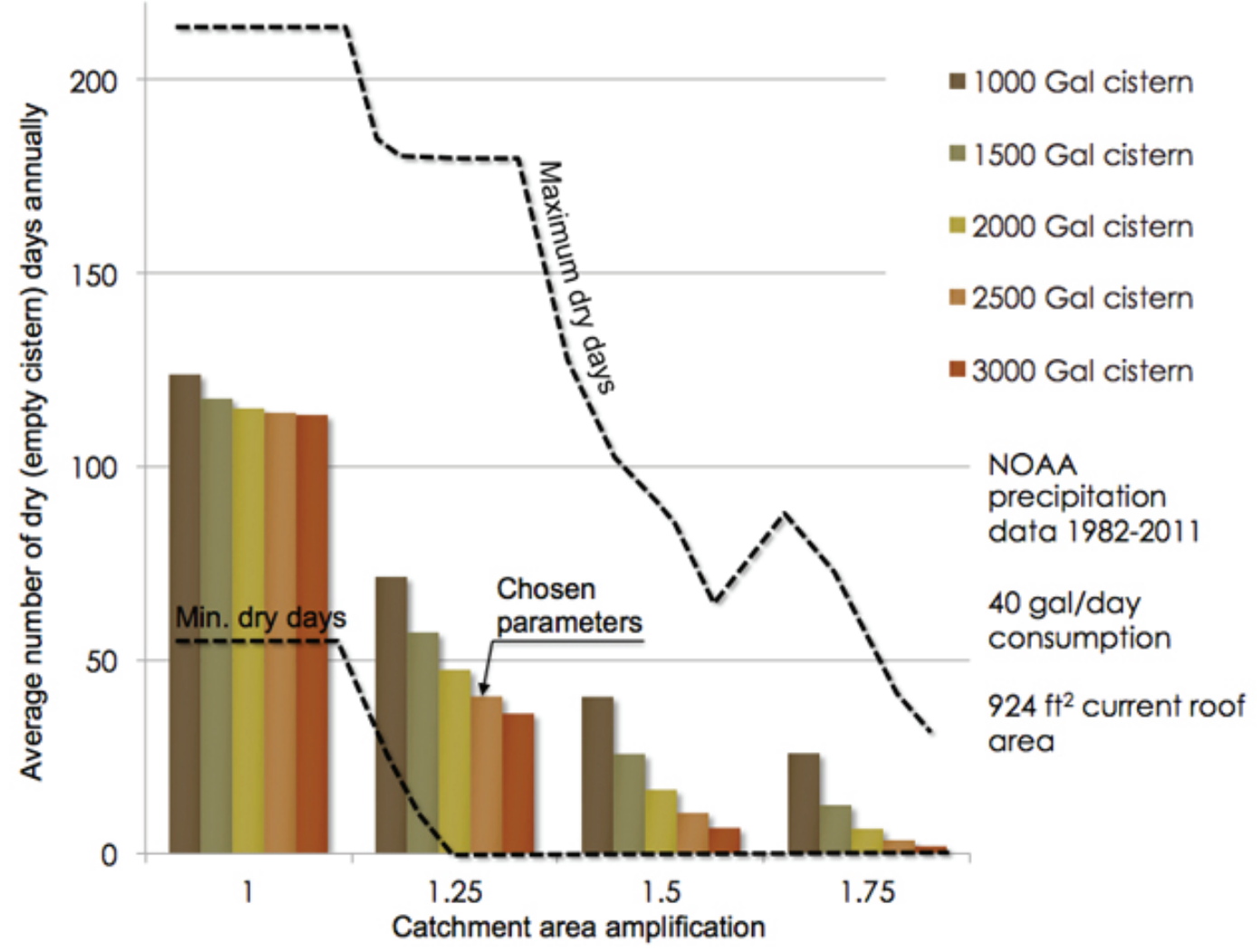

Figure 3. The minimum and maximum number of days without water in the cistern as a function of cistern size and catchment area increase in comparison to the current catchment area of $925 \mathrm{ft}^{2}$.

often the best choice. That option was impracticable for this retrofit, however, since light-colored unpainted metal has yet to be approved for use on Ann Arbor historic district folk Victorian buildings. Instead, we chose to replace the current shingles with painted metal shingles which appeared similar to the original shake shingle and thus received Ann Arbor Historic District Commission approval. Replacing the current asphalt shingles is necessary due to heavy metal content in the runoff that significantly exceeded background levels, as corroborated by $\mathrm{x}$-ray fluorescence observations of the shingle composition (Figure 4).

A retrofit project must also consider the current wastewater and stormwater pathways, such as significant runoff from typical non-native turfgrass draining to city sewers and the code-required municipal sewage connection within the building. To eliminate the majority of non-reclaimable wastewater from the home, the 


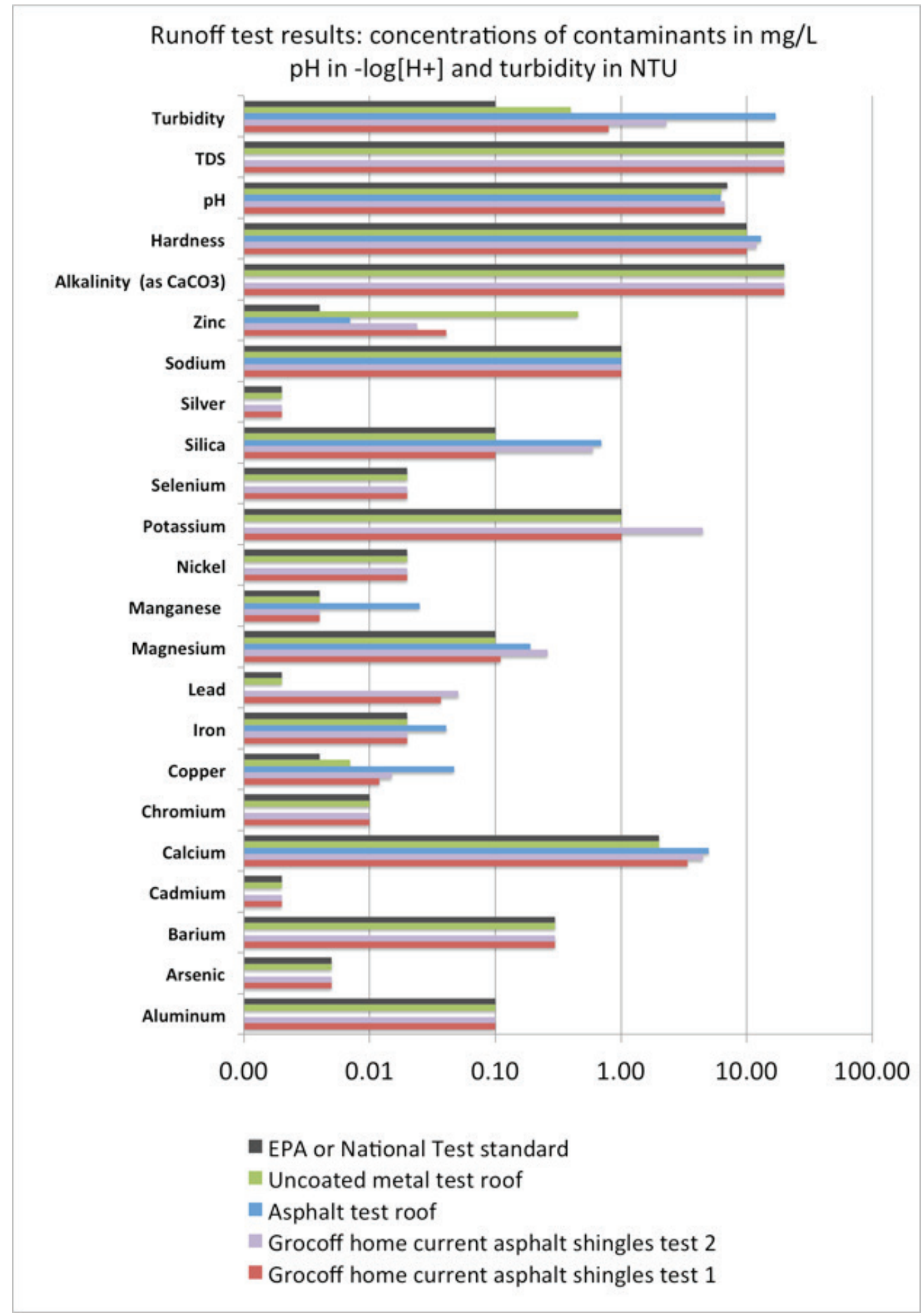

Figure 4. Water quality of rainwater runoff from roof at site and test roofs off-site. 
team determined that composting toilets would best meet the project needs, and we are considering how best to address challenges such as their required piping geometry and non-traditional appearance. To manage stormwater, we determined that drainage swales planted with restorative native species would be appropriate for the scale of the site (Neralla et al. 2000).

As sediment concentration in runoff from paved and vegetated surfaces would place undue pressure on a purification system for in-home potable quality (Gilbert 2006), we planted rain gardens (Figures 5 and 6) with native floodplain and wetland species to put this water to use. The rain gardens were sized to accommodate runoff from the largest storm expected every two years-runoff from onsite pavement as well as sidewalks and driveways uphill of the site. Trench drains were sized to divert this runoff into the rain gardens for infiltration rather than allow it to enter the adjacent 100-year floodplain or storm sewers. The team is currently considering ways to integrate these on-site native vegetation swales with a greywater treatment process in the future.

\section{Net Zero Energy Home}

The home, retrofit to operate at net-zero energy annually by the Grocoff family, could currently accommodate a $500 \mathrm{kWh}$ per year water management system without additional solar panels. This budget governs design of the in-home purification and distribution system. While not uncommon in the rural US, on-site water purification systems are often not designed with a net-zero energy budget in mind. We ruled out methods such as distillation and ozonation in favor of lower-energy UV disinfection. We also ruled out particulate filtration via reverse osmosis and slow sand filters due to high water losses and low flow rate, respectively, in favor of more efficient cartridge and granular activated carbon (GAC) filters. The system prototype achieves filtration and disinfection using a series of three passive cartridges that allow the passage of 50-, 5-, and 1-micron diameter particles. The water is then disinfected by a UV sterilizer operating at $9 \mathrm{gpm}$ with organic compounds removed by a passive 10-gallon granular activated carbon (GAC) tank that follows (Figure 7).

A key difference between this project's distribution strategy and that of conventional systems is a limited pump and UV bulb run time. Commercially available home purification systems typically include an on-demand pump, which would exceed this project's net-zero energy annual budget. However, 30-50 psi pressure at minimum flow rates must be provided to household fixtures at all times. While the 


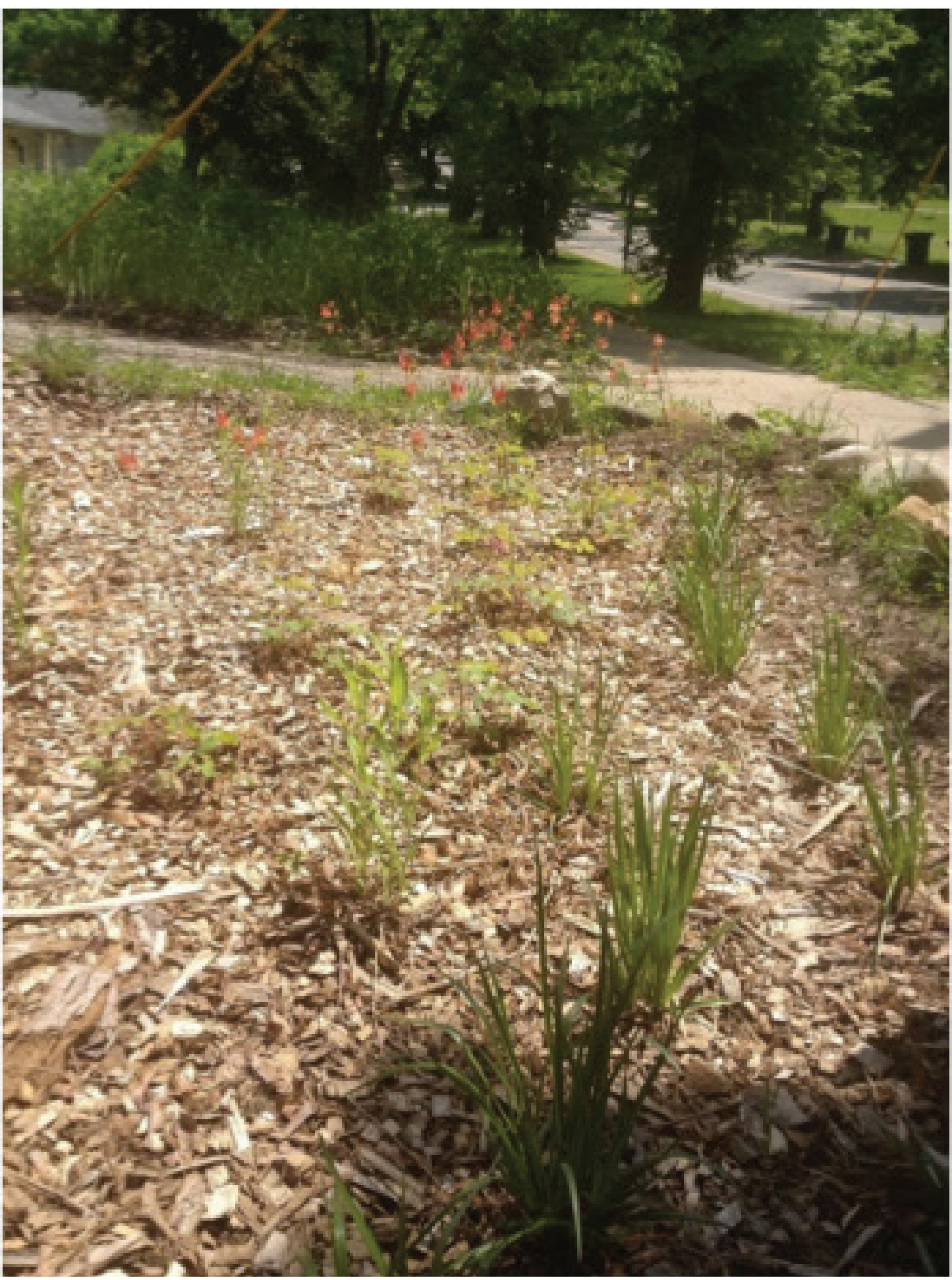

Figure 5. One of three on-site native plant raingardens after planting 


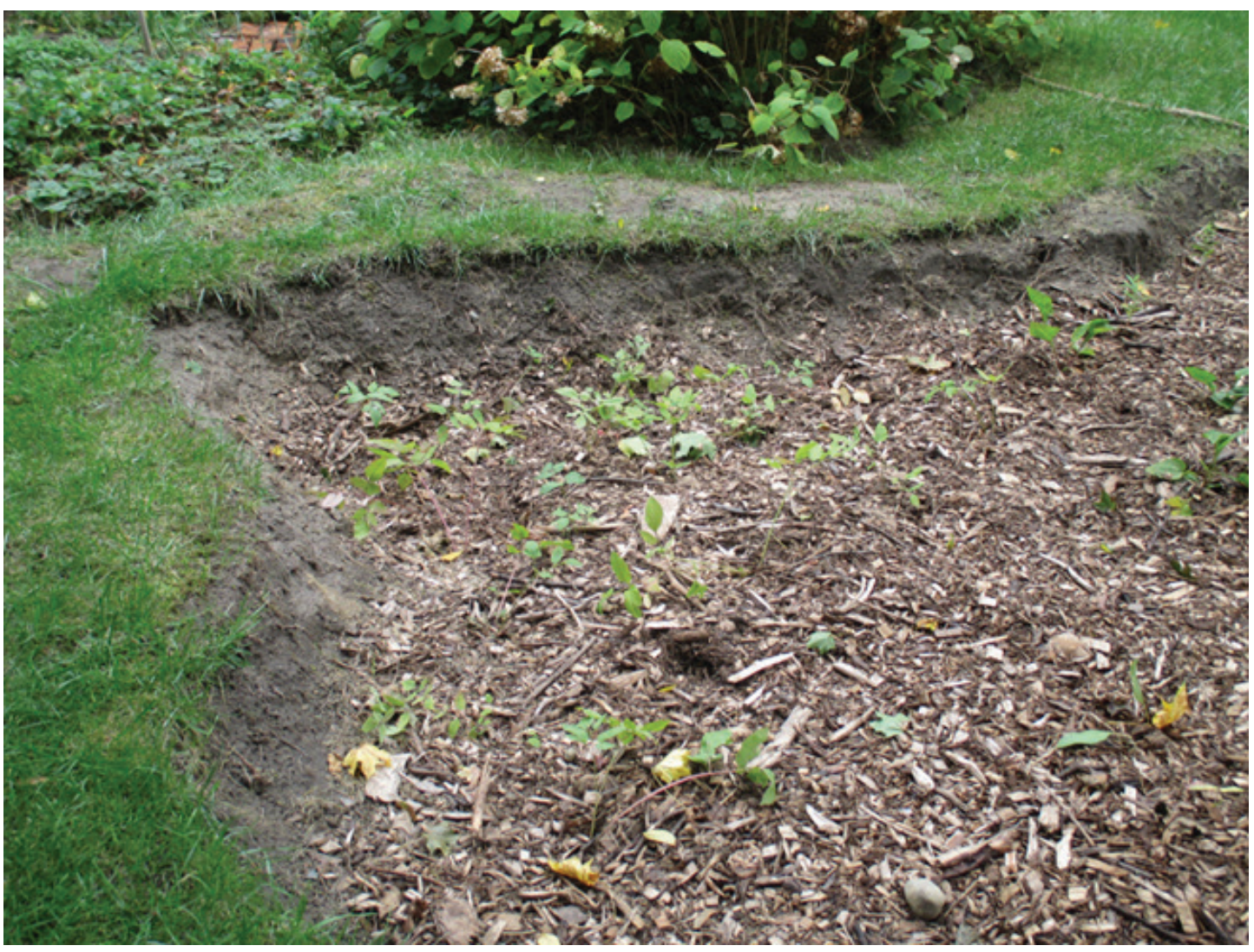

Figure 6. The deepest of three on-site native raingardens after planting.

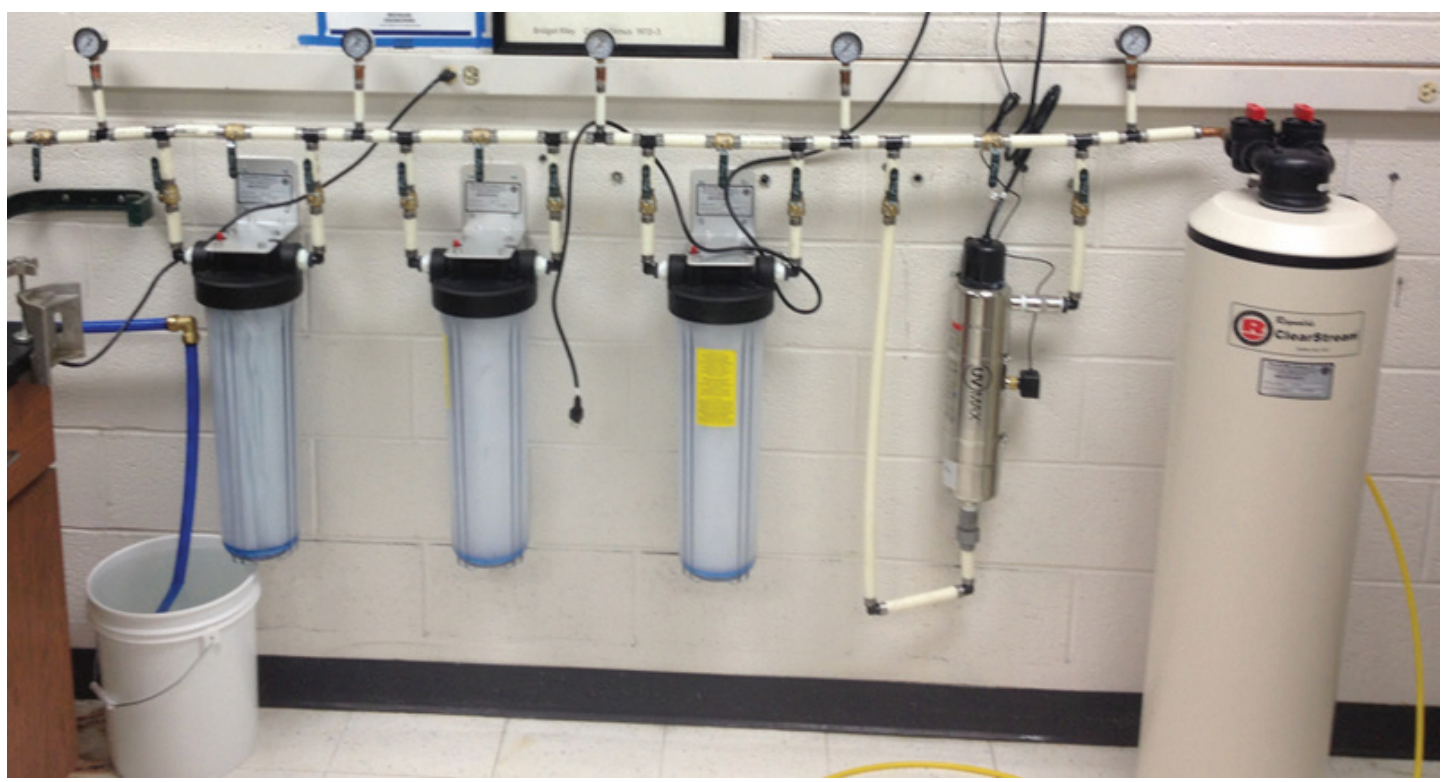

Figure 7. Home rainwater purification system designed and constructed by team in U-M lab for testing. 
minimum flow rate of the system is governed by usage patterns of home fixtures, the maximum is governed by the UV transmission requirements of the disinfection bulb, implying that a large pump can consume excess energy without improving system performance. Conducting energy simulations of water use patterns and pump run time allowed us to size a pressure tank to provide 24 hours of water on demand at a time. This pressure tank should be served by a pump and UV sterilizer that need only run for 40 minutes per day to pre-fill the tank. It is desirable to limit UV bulb operation to intervals of pump operation only, though most UV bulb manufacturers recommend running the bulb constantly to conserve service life. How to best save energy through pump and bulb downtime while simultaneously avoiding damage due to on/off cycling is a question that merits further testing.

\section{Municipal Regulations}

Designing and implementing a net-zero water system within a municipal setting presents new challenges, as homes are commonly required to remain tied to the city water and sewage system. Designers can consult some non-regulatory guidelines available from regions outside Michigan (USEPA 2013), but they should be aware that local codes often categorize rainwater as gray water or non-potable water. Under the Michigan Plumbing Code, this designation can prevent rainwater from being supplied to potable household fixtures or from contacting pipes and fittings that supply those fixtures (ICC 2011b). However, in Michigan a potablegrade rainwater harvesting system can be submitted for approval by a licensed Professional Engineer (P.E.), and then subsequently to the building inspector as an "alternative engineered design" (ICC 2011a). In this project, the designed net-zero water system will be implemented in stages to accommodate permitting milestones within this regulatory framework. Currently, the purification system is installed in a laboratory for testing, and upon P.E. and building inspector approval, the system and underground cistern will be installed at the home but treated rainwater will be supplied only to non-potable household fixtures and monitored for city evaluation. Finally, a greywater reclamation system will undergo testing, installation and on-site monitoring as well. 


\section{Widespread applicability}

The very characteristics that present significant challenges in this project - a netzero water retrofit operating within city limits and within a net-zero energy budget - make its findings more widely applicable in illuminating pathways of hybridizing de-centralized water infrastructure and centralized networks. Upgrading existing infrastructure will likely involve modification, rather than replacement of existing buildings, especially in urban areas. This case study on the retrofit of a single building reveals the key design considerations and implementation pathways that would lower the barriers to similar hybrid systems on a community-wide scale. To facilitate exploration of resilient decentralized energy and water systems, local plumbing codes could be extended to provide design guidelines for rainwater harvesting systems and to standardize precautions to protect consumer health. Studies of the cityscale environmental impacts of hybrid systems would also greatly help in informing the design of individual retrofits.

\section{Acknowledgements}

The U-M Living Buildings Team would like to thank Matthew Grocoff and family for their partnership, faculty advisor Prof. Steve Skerlos for guidance, and professional advisors Jamie Reynolds, Drew Lathin, Mike de Boer, Prof. Steve Wright and Mike Uhl for their support and insight. The team is grateful for the Ford College Community Challenge and the Dow Distinguished Award for Interdisciplinary Sustainability grants for making full-scale implementation possible.

\section{References}

ASCE (American Society of Civil Engineers). 2014. "2013 Report Card for America’s Infrastructure: Drinking Water.” Accessed September 2, 2014. http://www.infrastructurereportcard. org/a/\#p/drinking-water/overview.

Aupperlee, Aaron. 2013. "Sewage Overflow into Grand River a Public Health Concern, NoContact Advisory Issued.” MLive.com, April 18. http://www.mlive.com/news/grand-rapids/ index.ssf/2013/04/sewage_overflow_into_grand_riv.html.

Brabec, Elizabeth, Stacey Schulte, and Paul L. Richards. 2002. "Impervious Surfaces and Water Quality: A Review of Current Literature and Its Implications for Watershed Planning." Journal of Planning Literature 16 (4): 499-514. 
Cascadia GBC (Cascadia Green Building Council). 2011. "Regulatory Pathways to Net Zero Water: Guidance for Innovative Water Projects in Seattle.” https://ilbi.org/education/ResourcesDocuments/Reports-Docs/WaterDocs/regulatory-pathways-to-net-zero-water-report

Famiglietti, Jay. 2014. "How the West Was Lost." Water Currents, July 24. http://voices.nationalgeographic.com/2014/07/24/how-the-west-was-lost/.

Gilbert, Jennifer K., and John C. Clausen. 2006. "Stormwater Runoff Quality and Quantity from Asphalt, Paver, and Crushed Stone Driveways in Connecticut." Water Research 40 (4): 826-32.

Grable, Juliet. 2014. "Living Building Challenge: Historic Renovation - Project Profile." Home Power Magazine, February/March, 159.

ICC (International Code Council). 2011a. 2012 International Residential Code for One-and TwoFamily Dwellings. Washington, D.C.

- 2011b. 2012 International Plumbing Code. Country Club Hills.

ILFI (International Living Future Institute). 2014. "Living Building Challenge, the Tyson Living Learning Center.” http://living-future.org/case-study/tysonllc.

Nelson, Bryn. 2013. "The Bullitt Center in Seattle Goes Well Beyond Green.” New York Times, April 2. http://www.nytimes.com/2013/04/03/realestate/commercial/the-bullitt-center-inseattle-goes-well-beyond-green.html.

Neralla, Srinivasan, Richard W. Weaver, Bruce J. Lesikar, and Russell A. Persyn. 2000. "Improvement of Domestic Wastewater Quality by Subsurface Flow Constructed Wetlands.” Bioresource Technology 75 (1): 19-25.

NOAA (National Oceanic and Atmospheric Administration). 2013. National Climatic Data Center. http://www.nws.noaa.gov/view/states.php?state=MI.

NYDEC (New York Department of Environmental Conservation). 2014. "Aging Wastewater Treatment Infrastructure." January 1. Accessed November 1, 2014. http://www.dec.ny.gov/ chemical/69446.html.

USDA (U.S. Department of Agriculture). 1986. Urban Hydrology for Small Watersheds. Natural Resources Conservation Service, Conservation Engineering Division, Technical Release 55, June.

USEPA (U.S. Environmental Protection Agency). 2008. "WaterSense, Indoor Water Use in the U.S.” January 1. http://www.epa.gov/WaterSense/pubs/indoor.html.

—. 2013. "Rainwater Harvesting: Conservation, Credit, Codes, and Cost." January. http:// water.epa.gov/polwaste/nps/upload/rainharvesting.pdf. 